\title{
Occurrence of naphthenate deposition in crude oil production field offshore Niger Delta
}

\author{
Opeyemi Lawal ${ }^{1} \cdot$ Solomon A. Adekola ${ }^{1} \cdot$ Akinsehinwa Akinlua $^{2}$
}

Received: 16 July 2020 / Accepted: 20 October 2020 / Published online: 21 November 2020

(c) The Author(s) 2020

\begin{abstract}
Crude oil and produced water samples obtained from ten wells in an offshore field, Niger Delta, were analyzed, in order to determine the occurrence of naphthenates deposition in the field. Total acid number (TAN) and ${ }^{\circ}$ API of the crude oil samples, $\mathrm{pH}$ and metal ions concentrations of the produced water samples were determined. The results revealed that TAN values ranged from 0.47 to $1.01 \mathrm{mgKOH} / \mathrm{g}$ with $\mathrm{pH}$ of 6.9-8.9, which were above established threshold. The metal ions concentrations especially for $\mathrm{Ca}++$ and $\mathrm{Na}+$ were relatively high. These imply a high possibility of metal-naphthenate precipitation in the oil production facilities in this field.
\end{abstract}

Keywords Naphthenate $\cdot$ Crude oil $\cdot$ Produced water $\cdot$ Metal ions $\cdot$ Niger delta

\section{Introduction}

Naphthenate deposit or scale is presently one of the production chemistry challenges in the upstream crude oil sector with occurrence in different sites, both onshore and offshore, across the globe (Igwebueze et al. 2013). In recent years, there has been a worldwide increase in the production of acidic crudes that are rich in naphthenic acids (NAs) (Oliveira et al. 2013). Geochemical methods have proven useful in determining the presence of these acids in crude oil, which when present implies high potential or possibility of two major problems that are significant in process control as well as flow assurance in crude processing plants; naphthenic acid corrosion (NAC), and formation of naphthenates (naphthenic acid salts) which can either precipitate and form organic deposits (which block process lines and vessels thereby immensely contributing to flow assurance difficulties) or form interfacial active salts (soaps) that are prone to stabilized emulsions (Oliveira et al. 2013). Therefore, determining the presence of naphthenic acids in crude oil is the first step in detecting a portending deposit nucleation

Akinsehinwa Akinlua

aakinlua@oauife.edu.ng; geochemresearch@yahoo.com

1 Department of Geology, Obafemi Awolowo University, Ile-Ife, Nigeria

2 Fossil Fuels and Environmental Geochemistry, Department of Chemistry, Obafemi Awolowo University, Ile-Ife, Nigeria sequence and tackling these two aforementioned problems. For example, deposition of calcium naphthenate $(\mathrm{CaN})$ occurs when tetraprotic acids (tetra-acids with molecular weight above $1200 \mathrm{Da}$ ) are present in crude oil (Igwebueze et al. 2013).

Meanwhile, it is a known fact that the naphthenic acid phase behavior is a function of produced water composition and $\mathrm{pH}$. Both the tetraprotic acids and other naphthenic acids present in crude oil may react with the cations present in produced water at certain $\mathrm{pH}$ values and some specific set of conditions. For example, if there is sufficient calcium and the $\mathrm{pH}$ of produced water increases above $\mathrm{pH} 6$ (due to depressurization); there will be a competition of the different naphthenic acids to precipitate as scale (Meredith et al. 2000; Igwebueze et al. 2013). Cation size and hydrated water number have been used to explain the selectivity toward the divalent ions (Sundman et al. 2010). The reaction between the tetraprotic acids and produced water cations is very fast. These acids are surface active, and thus react to form a network with the calcium ions in the produced water (Nordgard et al. 2010). This network is very sticky, insoluble in oil or water and settles out as organic deposits. A specific set of conditions are necessary for eventual formation of these deposits (Arla et al. 2007). Sodium naphthenate is formed when naphthenic acid reacts with $\mathrm{Na}^{+}$in the produced water. Rousseau et al. (2001) described the naphthenate appearance mechanism as being dependent on the $\mathrm{pH}$ increase that occurs during crude oil production, due to carbon dioxide 
$\left(\mathrm{CO}_{2}\right)$ being evolved from the brine leading to an increase in produced water $\mathrm{pH}$ (Rousseau et al. 2001; Goldszal et al. 2002; Dyer et al. 2003; Shepherd et al. 2005). Calcium naphthenate formation has been observed at brine $\mathrm{pH}$ greater than about 6 (Goldszal et al. 2002; Rousseau et al. 2001; Turner and Smith 2005) whilst sodium carboxylate/emulsion has been seen at slightly higher brine $\mathrm{pH}$, that is, $~ 8.5$ (Gallup et al. 2005; Turner and Smith 2005). It has also been reported through several experiments that at low produced water $\mathrm{pH}$ values precipitation did not occur, as metal naphthenates do not precipitate when the solution $\mathrm{pH}$ value is below 6, with a buffered system (Laredo et al. 2004).

Naphthenates or organic deposition is known to be a big challenge in oil fields worldwide. The Niger Delta crude oils are not free of naphthenic acids, at the right $\mathrm{pH}$ conditions, the interaction of the naphthenic acids with cations in produced water would lead to formation of naphthenates. However, data on naphthenates deposition in Niger Delta oil fields are scarce. Therefore, in this preliminary study, oil and produced water samples from Field L02, a production field in the offshore Niger Delta, were evaluated in order to determine the level of risk for naphthenates deposition in this field.

\section{Geology of the study area}

The Niger Delta Basin is situated in the southern part of Nigeria where it isbordered by the Atlantic Ocean and lies between longitude $5^{\circ} \mathrm{E}-8^{\circ} \mathrm{E}$ and latitude $3^{\circ} \mathrm{N}-6^{\circ} \mathrm{N}$ (Evamy et al. 1978). The basin has a land area of about $141,639 \mathrm{~km}^{2}$ and sedimentary sequence of 39,600 ft. thickness (Knox and Omatsola 1989). It spans in an east-west direction from southwest Cameroun to the Okitipupa Ridge. The basin is framed by older mega tectonic elements such as the Calabar Flank which is the subsurface continuation of the Oban Massif borders at the eastern part. At the western part, the basin is truncated by the Dahomey Basin. The northwestern part is flanked by the Benin Flank which is a subsurface continuation of the West Africa shield. The basin is framed by the Abakaliki anticlinorium (fold belt) in the northeastern part (Evamy et al. 1978). The Delta has an arc shape (Short and Stauble 1967) and it is a high—energy constructive locate delta (Whiteman 1982). The basin is a major geological feature of significant petroleum exploration and production in Nigeria (Whiteman 1982), and it is presently leading oil province in Africa (Reijers 2011). It is the most important sedimentary basin in Nigeria from the view of size, thickness of sediments and economics as its petroleum reserve provides the largest percentage of foreign exchange earnings in the country. Three major cycles of sedimentation have been established in the Niger Delta as well as other parts of the southern Nigerian Sedimentary Basins (Short and Stauble 1967; Murat 1972). They are; the
Lower Cretaceous to Santonian Cycle (oldest), Campanian to Paleocene Cycle, and Paleocene/Lower Eocene to Recent cycle (youngest). The third sedimentary cycle, commencing in the Paleocene/Early Eocene, is responsible for the main part of the growth of the delta. The Niger Delta oil province with its commercial oilfields is confined to the area covered by a thick sequence of rocks belonging to the youngest (Tertiary) sedimentary cycle. The area that forms the scope of this study is within the shallow water blocks, located offshore in the southeastern coast of Nigeria. Samples used in this study were recovered from four different comingled samples representing localized blends of all wells in each of the four drilling platforms in the field; L02-D1 (A), L02-D2 (B), L02-D3 (C), and L02-D5 (D). Representative sample of the total blend of all of the aforementioned was also obtained at the comingling flow line, labeled E. For the sake of necessary analysis of produced water in this study, samples were importantly recovered from certain wells with high water cut. All these were within the Field L02.

\section{Materials and methods}

\section{Samples}

Crude oil samples and produced water samples used in this study were obtained from Field LO2 reservoir streams in the Niger Delta (Fig. 1). This crude oil samples were obtained from each of the drilling platforms in the field. The field has four drilling platforms with a total of 39 oil producing wells. Each platform produces from relatively different reservoirs in the same field. Total blend of all the platform productions was also assayed in this study.

\section{Determination of total acid number (TAN) of oil samples}

Standard solution of alcoholic $\mathrm{KOH}$ was prepared by adding $6 \mathrm{~g}$ of $\mathrm{KOH}$ to $1 \mathrm{~L}$ of anhydrous isopropyl alcohol and gently boiled for $10 \mathrm{~min}$ to effect solution. The solution was allowed to stand for 2 days and then filtered through a finesintered glass funnel. The solution was stored in a chemical resistant bottle and protected from $\mathrm{CO}_{2}$ with a guard tube containing soda lime. Standardization was achieved with $0.2 \mathrm{~g}$ potassium hydrogen phthalate and $80 \mathrm{~mL} \mathrm{CO}_{2}$-free water.

Potentiometric titration method (Fig. 2) was employed to obtain the total acid number (TAN) of the oil samples. $125 \mathrm{~mL}$ of alcoholic $\mathrm{KOH}$ solution was dispensed into the titration vessel and $3 \mathrm{~g}$ of crude oil sample was added into the vessel, electrode was immersed in the mixture. $\mathrm{KOH}$ delivery tube was also inserted into the titration vessel. Titration was effected until the end point was reached. 
Fig. 1 Map of Nigeria oil-rich blocks showing the study area, Field L02 (from Vavon et al. 2013)

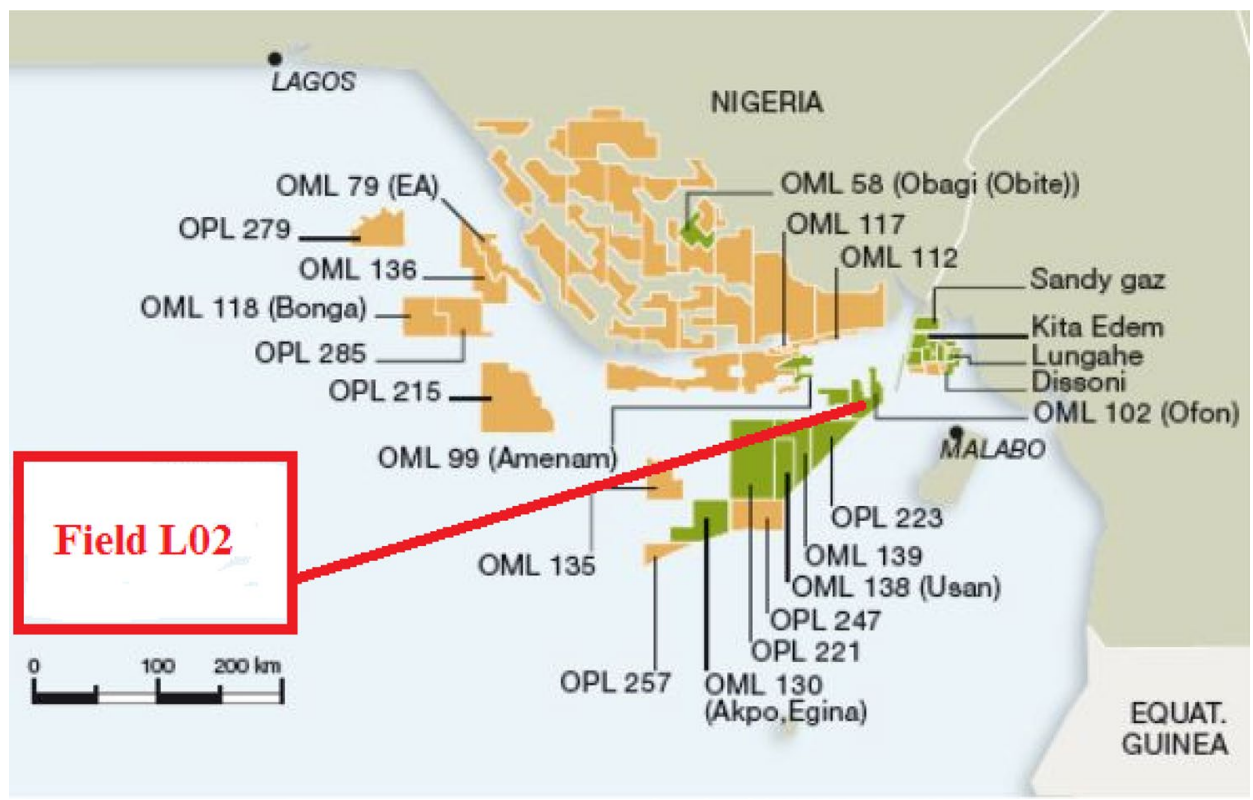

Fig. 2 Experimental set-up for determination of total acid number of crude oil samples from field L-02

Precautions were taken to flush out all bubbles from the $\mathrm{KOH}$ delivery tube. Also, after the titration, the electrode and burette tip were rinsed with solvent, then with water for $5 \mathrm{~min}$, then again with solvent. Blank titration was carried out on the alcoholic $\mathrm{KOH}$ solution without sample.

\section{Determination of cations content of produced water samples}

Standard solutions of the calcium, sodium and magnesium ions were prepared from their stock solutions. The stock solutions were diluted with deionized distilled water to prepare each working solution for calibration. The concentrations of the cations in the produced water samples were determined by atomic absorption spectrometry. AA500 atomic absorption spectrometer by PG Instrument was employed. AA500 is equipped with both Flame Atomizer and Graphite Atomizer. The AAS is equipped with automatic 8 hollow cathode lamp turret controlled and optimized by the AAWin3 software. A deuterium-arc lamp was used for background correction. A universal autosampler was mounted on the front of the AA500 instrument. The analysis was performed according to the PG Instrument manual.

Spectrophotometric method was used for measurement of ferrous ion with the use of HACH spectrophotometer DR 2800. Method 255 measurement was carried out at $510 \mathrm{~nm}$. The FerroVer iron reagent is a powder pillow which when dissolved in $25 \mathrm{~mL}$ of the sample (contained in a cuvette) converts all soluble iron and most insoluble forms of iron in the sample to soluble ferrous ion. The ferrous ion reacts with phenanthroline indicator in the reagent to form an orange color in proportion to the iron concentration. The result is measured at $510 \mathrm{~nm}$ in the $\mathrm{HACH} 2800$ spectrophotometer.

\section{Results and discussion}

\section{Geochemical implication of total acid number of crude oil}

The total acid number (TAN) measurement has been used as an indication of the acid composition of crude oil. It has been established that the acidity of crude oils is mainly due to the presence of significant quantities of naphthenic 
acids (Passade-Boupat et al. 2012). The total acid number of crude oil samples from Field L02 ranges from 0.47 to 1.01 (Table 1). These relatively high TAN values suggest that the naphthenic acid content of the crude oil samples can intrinsically induce organic deposition. The results showed that there is no linear correlation between the values of TAN and ${ }^{\circ} \mathrm{API}$ (Table 1 ) because it is expected that TAN value increases with decrease ${ }^{\circ} \mathrm{API}$.

Mohammed (2010) reported that most of the calcium naphthenate-forming crude oils have higher TAN $(0.20-2.50 \mathrm{mg} \mathrm{KOH} / \mathrm{g})$, whereas the sodium carboxylate/emulsion forming crude oil samples showed low $(0.40-0.41 \mathrm{mg} \mathrm{KOH} / \mathrm{g})$ to moderate TAN $(0.48-0.50 \mathrm{mg}$ $\mathrm{KOH} / \mathrm{g}$ ), although some calcium naphthenate forming crude oil may have a low TAN. A reasonable guide was established, that is, the higher the TAN value then the lower the API gravity, and subsequently, the tendency of that crude oil sample to form calcium naphthenate deposits during oil production. Although this is not always the case, as there are some crude oil samples with low TAN and API still form calcium naphthenate. Therefore, formation of calcium naphthenate or sodium carboxylate/emulsion is much more associated with the particular acid composition in the crude. Since TAN values for the crude oil samples in this study range from 0.47 to $1.01 \mathrm{mg} \mathrm{KOH} / \mathrm{g}$ and only samples A and $\mathrm{J}$ have TAN values less than $0.50 \mathrm{mg} \mathrm{KOH} / \mathrm{g}$, thus it suggests that these oil samples would induce calcium naphthenate formation, which is usually a solid organic deposit with the attendant consequences. This result indicates that Field
L02 would have naphthenate deposition and its associated challenges.

\section{Effect of $\mathrm{pH}$ and metal ions concentration on naphthenate deposition}

The $\mathrm{pH}$ of produced water samples from Field L02 range from 6.9 to 8.9, which are above the threshold value of 6.0 (Table 1). The values of TAN in crude oil samples in Field L02 indicate the presence of naphthenic acids in the oil samples (Table 1). Produced water composition is known to play a significant role in the basic naphthenate formation mechanism. Therefore, the $\mathrm{pH}$ of the produced water samples can induce the formation of naphthenates in this field, in other words, the $\mathrm{pH}$ of Field L02 production system, as measured, presents a good condition for metal naphthenate precipitation.

The profile of metal ions concentrations of the produced water samples from Field L02 (Table 1) reveals that the levels of $\mathrm{Ca}^{++}, \mathrm{Na}^{+}, \mathrm{Mg}^{++}$and $\mathrm{Fe}^{++}$range from 18.28 to $557.97,78.30$ to $11,380,2.22$ to 810 and 0.28 to $13.48 \mathrm{mg} / \mathrm{L}$, respectively. $\mathrm{Ca}^{++}$and $\mathrm{Na}^{+}$have average high values; Both $\mathrm{Ca}^{++}$and $\mathrm{Na}^{+}$have been implicated in naphthenate formation that resulted organic deposit in production facilities. Calcium naphthenate $(\mathrm{CaN})$ formation has been observed at produced water with $\mathrm{pH}$ value greater than 6 (Rousseau et al. 2001; Goldszal et al. 2002; Turner and Smith 2005) while sodium naphthenate (NaN) has been observed at produced water with $\mathrm{pH}$ value of
Table 1 Geochemical properties of crude oil and produced water samples of Field L02, offshore Niger Delta

\begin{tabular}{lllllllll}
\hline Sample & $\begin{array}{l}\text { TAN }(\mathrm{mg} \\
\mathrm{KOH} / \mathrm{g})\end{array}$ & ${ }^{\circ} \mathrm{API}$ & $\mathrm{pH}$ & $\mathrm{pH}^{*}$ & $\mathrm{Ca}^{++}(\mathrm{mg} / \mathrm{L})$ & $\mathrm{Mg}^{++}(\mathrm{mg} / \mathrm{L})$ & $\mathrm{Na}^{+}(\mathrm{mg} / \mathrm{L})$ & $\mathrm{Fe}^{++}(\mathrm{mg} / \mathrm{L})$ \\
\hline A & 0.49 & 37.6 & 8.2 & NA & 97.26 & 2.22 & 105.2 & 0.83 \\
B & 0.54 & 35.6 & 7.9 & NA & 22.18 & 3.02 & 89.91 & 1.15 \\
C & 0.66 & 40.1 & 8.7 & NA & 26.81 & 2.74 & 98.46 & 13.48 \\
D & 0.50 & 40.1 & 6.9 & NA & 130.4 & 2.38 & 78.3 & 3.14 \\
E & 0.58 & 39.8 & 8.2 & 7.4 & 112.48 & 2.89 & 99.92 & 1.48 \\
F & 0.61 & 32.2 & 8.9 & NA & 69.97 & 2.79 & 100.5 & 0.35 \\
G & 0.50 & 35.7 & 8.6 & NA & 18.28 & 2.79 & 101.8 & 2.66 \\
H & 0.60 & 38.4 & 8.1 & NA & 101.8 & 1.99 & 82.18 & 2.77 \\
I & 1.01 & 36.8 & 8.2 & NA & 557.9 & 3.11 & 94.64 & 3.18 \\
J & 0.47 & 42.3 & 8.4 & NA & 318 & 810 & 11,380 & 0.28 \\
\hline
\end{tabular}

$p H^{*} \mathrm{pH}$ measured after acetic acid treatment

$T A N$ total acid number

${ }^{\circ}$ API API gravity

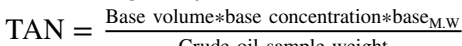

where the base concentration $_{\text {is the molar concentration of the base and base }}$ M.W is the molecular weight of the base used

The mathematical expression for the total acid number (TAN) calculation after the titration was carried out as:

TAN $=\frac{\text { (Titrant consumption-Solvent blank) } * \text { Molarity of titrant } * \text { Factor on titrant } * \text { Molar mass of KOH (56.106) }}{\text { Sample weight }}$ 
about 8.5 (Gallup et al. 2005; Turner and Smith 2005). Therefore, with $\mathrm{pH}$ range of 6.9-8.9 and relatively high concentrations of calcium and sodium ions, Field L02 is at a risk of $\mathrm{CaN}$ and $\mathrm{NaN}$ deposition (Fig. 3). Compared with the concentrations of calcium and sodium ions, the concentrations of magnesium and ferrous ions in produced water samples in this field, though in high $\mathrm{pH}$ environment (Fig. 4) is not likely to induce naphthenate formation. Organic deposit $(\mathrm{CaN})$ that results from the reaction $\mathrm{Ca}^{++}$ and naphthenic acid are known to be hard solids while deposit (NaN) from the reaction of $\mathrm{Na}^{+}$and naphthenic acid is quite soft and also form emulsion at lower concentrations. In essence, the relatively high concentrations of these ions would influence naphthenates precipitation in the production facilities of Field L02. Igwebueze et al. (2013) identified calcium naphthenate (CaN) scale as the major component in the solids in an offshore field in the Niger Delta. Calcium ion concentration in the produced water in the offshore field that witnessed heavy metalnaphthenate deposits was $250 \mathrm{mg} / \mathrm{L}$, and if compared with certain wells (D. E. I and J) in Field L02 with $\mathrm{Ca}^{++}$ concentrations of $130.40,112.48,557.97$ and $318 \mathrm{mg} / \mathrm{L}$, respectively (Table 1), Field L02 is therefore at high risk of organic deposition. Hence, high concentration of $\mathrm{Ca}^{++}$ and $\mathrm{Na}^{+}$in Field L02 produced water (brine) can aid formation of metal-naphthenate deposits that could impede production of crude oil in this field.

Impact of acetic acid treatment on $\mathrm{pH}$ of produced water was investigated; a sample of produced water was taken at well $\mathrm{E}$ in Field L02. The result shows the $\mathrm{pH}$ after acetic acid treatment was 7.40 which is lower compared with the $\mathrm{pH}$ of the sample before acetic acid treatment (8.2). The lowering of $\mathrm{pH}$ indicates that the acetic acid treatment is effective and favorable to inhibition of metal-naphthenate deposition.

\section{Conclusions}

The values of total acid number of the crude oil samples obtained in Field L02 indicate high acidic composition which is indicative of naphthenic acid content. The $\mathrm{pH}$ values of the produced water samples were all above the threshold value of 6.0. The concentrations of metal ions in the produced water samples from Field L02 are relatively high especially the concentrations of $\mathrm{Ca}^{++}$and $\mathrm{Na}^{+}$, coupled with the high $\mathrm{pH}$ values, can aid the formation of metal-naphthenate formation. The results of these parameters indicate occurrence of metal-naphthenate precipitation at the present operating conditions for Field L02 production. Field L02 seems to be experiencing slight deposition already which has the potential to grow into bulk deposition if not properly
Fig. 3 Cross plot of $\mathrm{pH}$ versus concentration of metal ions $\left(\mathrm{Na}^{+}\right.$and $\left.\mathrm{Ca}^{++}\right)$to reveal the possibility of calcium naphthenate and sodium napthenate formation

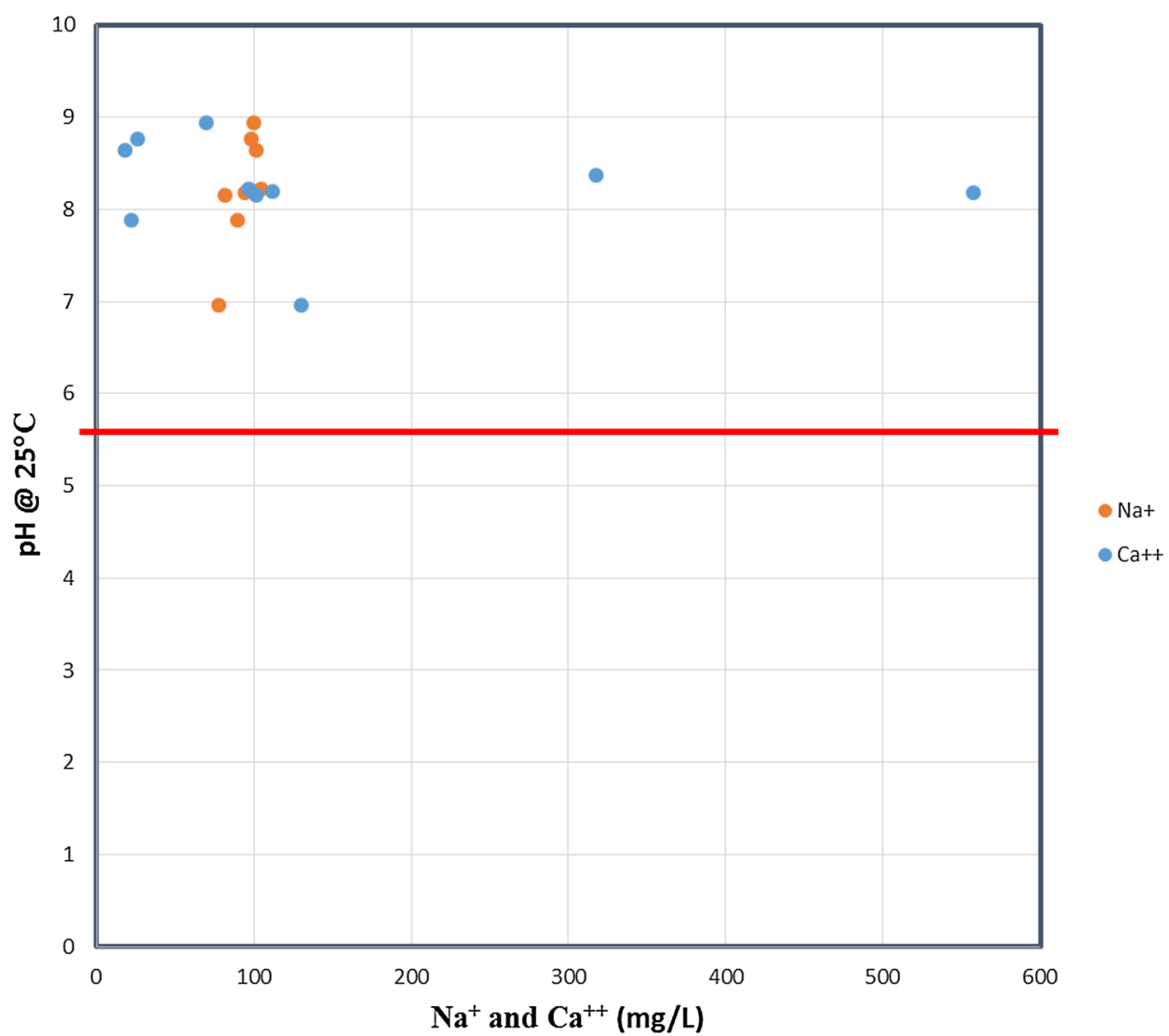
للعلينة الملك عبدالكنية العزيز 
Fig. 4 Cross plot of $\mathrm{pH}$ versus concentrations of $\mathrm{Mg}^{++}$and $\mathrm{Fe}^{++}$to evaluate the influence of these ions on naphthenate formation

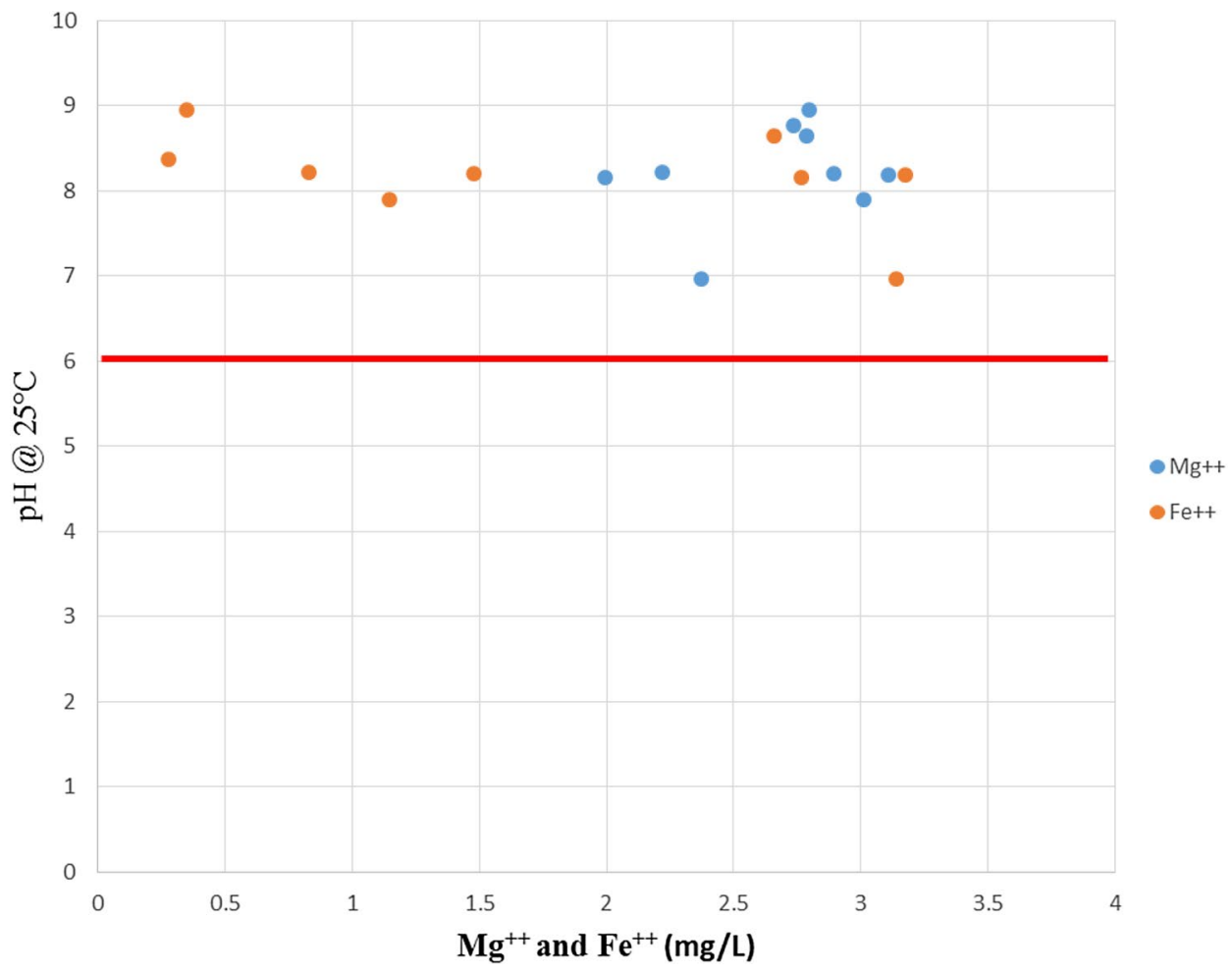

addressed. Acetic acid treatment was effective to mitigate formation of metal naphthenate deposition.

Acknowledgements The authors appreciate Franklin Uzokwe, Jan deSmedt, Maximus Ehileme, Nicolas Musset and Chikwe Igwe for their assistance during this study.

Funding No funding was received for this project.

Conflicts of interest/Competing interests No conflict of interest.

Open Access This article is licensed under a Creative Commons Attribution 4.0 International License, which permits use, sharing, adaptation, distribution and reproduction in any medium or format, as long as you give appropriate credit to the original author(s) and the source, provide a link to the Creative Commons licence, and indicate if changes were made. The images or other third party material in this article are included in the article's Creative Commons licence, unless indicated otherwise in a credit line to the material. If material is not included in the article's Creative Commons licence and your intended use is not permitted by statutory regulation or exceeds the permitted use, you will need to obtain permission directly from the copyright holder. To view a copy of this licence, visit http://creativecommons.org/licenses/by/4.0/.

\section{References}

Arla D, Sinquin A, Palermo P, Hurtevent C, Graciaa A, Dicharry C (2007) Influence of $\mathrm{pH}$ and water content on the type and stability of acidic crude oil emulsions. Energy Fuels 21:1337-1342

Dyer SJ, Graham GM, Arnott C (2003) Naphthenate scale formation - examination of molecular controls in idealised systems, SPE
80395, presented at the 5th International Symposium on Oilfield Scale, Aberdeen, UK, January 29-30

Evamy BD, Haremboure J, Kamerling P, Knaap WA, Molloy FA, Rowlands H (1978) Hydrocarbon habitat of Tertiary Niger Delta. AAPG Bull 62:277-298

Gallup DG, Smith PC, Star JF, Hamilton SH (2005) West Seno deepwater development case history, production chemistry, SPE 92969, presented at the International Symposium on Oilfield Chemistry, Houston, Texas, USA, February 2-4

Goldszal A, Hurtevent C, Rousseau G (2002) Scale and naphthenate inhibition in deepoffshore fields, SPE 74661, presented at the 4th International Oilfield Scale Symposium, Aberdeen, UK, January 30-31

Igwebueze C, Oduola L, Smith O, Vijn P, Shephered AG (2013) Calcium Naphthenate solid deposit identification and control in offshore Nigerian field, SPE 164055, presented at the SPE International Symposium on Oilfield Chemistry, Woodlands, Texas, USA, 8-10 April 2013

Knox GJ, Omatsola EM (1989) Development of Cenozoic Niger Delta in terms of the 'Escalator Regression' model and impact on hydrocarbon distribution: proceeding coast Low lands geology and KNGM symposium Geotechnology, 1987, Dordrecht, Kluwer, p 81

Laredo GC, Lopez CR, Alvarez RE, Cano JL (2004) Naphthenic acids, total acid number and sulfur content profile characterization in Isthmus and Maya crude oils. Fuel 83:1689-1695

Meredith W, Kelland SJ, Jones DM (2000) Influence of biodegradation on crude oil acidity and carboxylic acid composition. Org Geochem 31:1059-1073

Mohammed MA (2010) Characterization, modelling, prediction and inhibition of naphthenate deposits in oilfield production. Institute of Petroleum Engineering, Herriot Watt University

Murat RC (1972) Stratigraphy and paleogeography of the cretaceous and lower tertiary in Southern Nigeria. In: Dessauvagie TF, Whiteman AJ (eds) Africa geology. Ibadan University Press, Ibadan, pp 251-266 
Nordgard EL, Hanneseth AMD, Sjoblom J (2010) Inhibition of calcium naphthenate. Experimental methods to study the effects of commercially available Naphthenate Inhibitors. J Dispers Sci Technol 31:668-675

Oliveira MCK, Rosário FF, Bertelli JN, Pereira RCL, Albuquerque FC, Marques LCC (2013) SPE 166235 flow assurance solutions to mitigate naphthenates problems in crude oil production, 1-10

Passade-Boupat N, Gonzalez MR, Benjamin Brocart B, Hurtevent C, Palermo T (2012) Risk assessment of calcium naphthenates and separation mechanisms of acidic crude oil. SPE 155229

Reijers TJA (2011) Stratigraphy and sedimentology of the Niger Delta. Geologos 17(3):133-162

Rousseau G, Zhou H, Hurtevent C (2001) Calcium carbonate and naphthenate mixed scale in deep-offshore fields. SPE 68307 presented at the International Symposium on Oilfield Scale, Aberdeen, 30-31 January 2001

Shepherd AG, Thomson G, Westacott R, Neville A, Sorbie KS (2005) A mechanistic study of naphthenate scale formation, SPE 93407, presented at the SPE International Symposium on Oilfield Chemistry, Houston, Texas, USA
Short KC, Stauble AJS (1967) Outline of geology of niger delta. AAPG Bull 51:761-779

Sundman O, Simon S, Nordgard EL, Sjoblom J (2010) Study Of The aqeous chemical interactions between a synthetic tetra-acid and divalent cations as a model for the formation of metal naphthenate deposits. Energy Fuels 24:6054-6060

Turner MS, Smith PC (2005) Control on soap scale formation, including naphthenate soaps - drivers and mitigation, SPE 94339

Vavon N, Phok A, Delaunay E (2013) Operating manual, OFON phase 2 project, Book 1, Part C - OFP2 Operating Manuals

Whiteman AJ (1982) Nigeria: its petroleum geology, resources and potentials. Graham and Trotman, London, 394 pp

Publisher's Note Springer Nature remains neutral with regard to jurisdictional claims in published maps and institutional affiliations. 